\title{
Retrieval of water vapor profile in the mesosphere from satellite ozone and hydroxyl measurements by the basic dynamic model of mesospheric photochemical system
}

\author{
M. Y. Kulikov ${ }^{1}$, A. M. Feigin ${ }^{1}$, and G. R. Sonnemann ${ }^{2}$ \\ ${ }^{1}$ Institute of Applied Physics of the Russian Academy of Science, Ulyanov Str. 46, 603950, Nizhny Novgorod, Russia \\ ${ }^{2}$ Leibniz-Institute of Atmospheric Physics at the University Rostock in Kühlungsborn, Schloss-Str. 6, 18225 Ostseebad \\ Kühlungsborn, Germany
}

Received: 9 December 2008 - Published in Atmos. Chem. Phys. Discuss.: 4 March 2009

Revised: 14 October 2009 - Accepted: 14 October 2009 - Published: 2 November 2009

\begin{abstract}
We propose an indirect method for retrieving a number of significant minor gas constituents of the atmosphere. The technique is based on the use of so-called basic dynamic models of atmospheric photochemical systems simplified mathematically correctly in a special manner. It is applied to a mesospheric system describing day evolution of key minor gas constituents at these heights. We take as initial data experimental data of the CRISTA-MAHRSI satellite campaign of August 1997 during which ozone and hydroxyl $\left(\mathrm{O}_{3}\right.$ and $\left.\mathrm{OH}\right)$ concentrations were measured simultaneously. It is demonstrated that the use of the basic dynamic model allows retrieval of vertical distribution (within the $53-85 \mathrm{~km}$ range of heights) of water vapor concentration that is one of the control parameters of the mesospheric photochemistry.
\end{abstract}

\section{Introduction}

Observation of minor gas constituents (MGC) is traditionally one of the fundamental problems in investigations of the Earth's atmosphere. MGC evolution is controlled by photochemical processes which, being one of the basic sources of air heating in the middle atmosphere, influence the majority of atmospheric parameters and govern one of the key mechanisms of anthropogenic action on processes in an atmosphere.

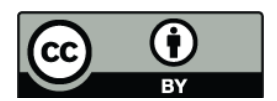

Correspondence to: M. Y. Kulikov (kulm@appl.sci-nnov.ru)
As the number of MGCs that can be measured directly and regularly is still rather scanty, indirect methods are a useful tool. They are based on using a priori knowledge about possible relationship between measured and inferred characteristics and allow obtaining additional information about the most significant atmospheric MGCs from available experimental data. Mathematical models of photochemical systems (equations of chemical kinetics for MGC concentrations involving transport processes) may be regarded to be the main candidates for a "supplier" of a priori relationships. These models have been developed and verified for most regions of the Earth's atmosphere. However, high dimension hinders wide application of these models for obtaining information about concentrations on non-measured and/or unmeasurable MGCs. Atmospheric photochemical systems (APCS) contain, as a rule, several tens and more chemical constituents reacting with each other and evolution of these systems depends on a large amount of parameters. In this work we propose a method for retrieving atmospheric MGC concentrations that are not measured directly. The method is based on using mathematically correctly simplified APCS models referred to, following the work by Feigin and Konovalov (1996), as basic dynamic models (BDM). BDMs retain, within the considered region of the parameter values, basic qualitative and quantitative properties of a "complete" system and include a minimum possible number of dynamic variables described by differential equations. The key idea of constructing such models is to divide variables of the system (concentrations of chemical constituents) into two groups according to the relationship between characteristic time of their evolution, " $\tau$ ", and time scale of the studied

Published by Copernicus Publications on behalf of the European Geosciences Union. 
Table 1. List of reactions.

\begin{tabular}{ll}
\hline (R1) $\mathrm{O}+\mathrm{OH}+\mathrm{M} \rightarrow \mathrm{HO}_{2}+\mathrm{M}$ & (R11) $\mathrm{O}+\mathrm{O}+\mathrm{M} \rightarrow \mathrm{O}_{2}+\mathrm{M}$ \\
(R2) $\mathrm{H}+\mathrm{HO}_{2} \rightarrow \mathrm{O}_{2}+\mathrm{H}_{2}$ & (R12) $\mathrm{O}_{3}+\mathrm{H} \rightarrow \mathrm{O}_{2}+\mathrm{OH}$ \\
$\left(\right.$ R3) $\mathrm{OH}+\mathrm{HO}_{2} \rightarrow \mathrm{O}_{2}+\mathrm{H}_{2} \mathrm{O}$ & $\left(\right.$ R13) $\mathrm{O}_{3}+\mathrm{OH} \rightarrow \mathrm{O}_{2}+\mathrm{HO}_{2}$ \\
$(\mathrm{R} 4) \mathrm{O}+\mathrm{OH} \rightarrow \mathrm{O}_{2}+\mathrm{H}$ & $(\mathrm{R} 14) \mathrm{H}+\mathrm{HO}_{2} \rightarrow 2 \mathrm{OH}$ \\
$(\mathrm{R} 5) \mathrm{O}+\mathrm{HO} \mathrm{O}_{2} \rightarrow \mathrm{O}_{2}+\mathrm{OH}$ & $(\mathrm{R} 15) \mathrm{OH}+\mathrm{OH} \rightarrow \mathrm{O}+\mathrm{H}_{2} \mathrm{O}$ \\
$(\mathrm{R} 6) \mathrm{O}_{2}+\mathrm{H}+\mathrm{M} \rightarrow \mathrm{HO}_{2}+\mathrm{M}$ & $(\mathrm{R} 16) \mathrm{O}_{3}+\mathrm{h} \nu \rightarrow \mathrm{O}_{2}+\mathrm{O}\left({ }^{1} \mathrm{D}\right)$ \\
$(\mathrm{R} 7) \mathrm{H}_{2} \mathrm{O}+\mathrm{h} \nu \rightarrow \mathrm{H}+\mathrm{OH}$ & $(\mathrm{R} 17) \mathrm{OH}+\mathrm{H}+\mathrm{M} \rightarrow \mathrm{H}_{2} \mathrm{O}+\mathrm{M}$ \\
$(\mathrm{R} 8) \mathrm{O}_{2}+\mathrm{h} \nu \rightarrow 2 \mathrm{O}$ & $(\mathrm{R} 18) \mathrm{H}+\mathrm{HO} \mathrm{O}_{2} \rightarrow \mathrm{H}_{2} \mathrm{O}+\mathrm{O}$ \\
$\left(\right.$ R9) $\mathrm{O}+\mathrm{O}_{2}+\mathrm{M} \rightarrow \mathrm{O}_{3}+\mathrm{M}$ & $(\mathrm{R} 19) \mathrm{O}\left({ }^{1} \mathrm{D}\right)+\mathrm{M} \rightarrow \mathrm{O}+\mathrm{M}$ \\
$(\mathrm{R} 10) \mathrm{O}+\mathrm{O}_{3} \rightarrow 2 \mathrm{O}_{2}$ & $(\mathrm{R} 20) \mathrm{H}_{2} \mathrm{O}+\mathrm{O}\left({ }^{1} \mathrm{D}\right) \rightarrow 2 \mathrm{OH}$ \\
\hline
\end{tabular}

$\mathrm{M}$ - molecule of air

phenomenon, $\tau_{0}$. Variables of the first group are "fast": $\tau \ll \tau_{0}$. Taking into consideration dissipativity of APCS, they are supposed to be in the state of instantaneous stable equilibrium. Their "instantaneously equilibrium" values are determined from a system of algebraic equations obtained by equating to zero time derivatives in the corresponding equations of chemical kinetics of the initial (complete) system. These values are generally functions of parameters and of the slow (dynamic) variables referred to the second group whose evolution with characteristic time $\tau \approx \tau_{0}$ is described by differential equations. Thus, the procedure of BDM construction allows one to find asymptotically correctly a maximum possible number of algebraic relationships between constituents of the considered photochemical system. It is quite apparent that these relationships are the most convenient tool for inferring from available data of experiments information about significant MGCs of the atmosphere. In addition, if all dynamic variables of the BDM are inferred from algebraic equations, there arises a possibility to use a system of BDM differential equations for seeking values of the most important ("control") parameters determining the evolution of MGC concentrations.

In this work the above approach is applied to a mesospheric photochemical system (MPCS) that describes evolution of key MGCs $\left(\mathrm{O}, \mathrm{O}\left({ }^{1} \mathrm{D}\right), \mathrm{O}_{3}, \mathrm{H}, \mathrm{OH}, \mathrm{HO}_{2}\right)$ of the Earth's mesosphere (50-90 km heights). We take as initial data experimental data of the CRISTA-MAHRSI satellite campaign of August 1997 during which ozone and hydroxyl $\left(\mathrm{O}_{3}\right.$ and $\left.\mathrm{OH}\right)$ concentrations were measured simultaneously. We demonstrate that the use of the MPCS BDM allows retrieval of vertical distribution (within the 53-85 km range of heights) of $\mathrm{H}_{2} \mathrm{O}$ concentration that is one of the control parameters of the MPCS.

\section{MPCS and the used models, general description of the method of $\mathrm{H}_{2} \mathrm{O}$ retrieval by $\mathrm{O}_{3}$ and $\mathrm{OH}$ measure- ments}

A complete MPCS usually includes about a hundred chemical reactions with participation of more than twenty chemical constituents of the mesosphere (see, e.g., Brasseur and Solomon, 1986; Fichtelmann and Sonnemann, 1989). These constituents have different lifetimes, and chemical reactions running with their participation generally make different contributions to the evolution of this photochemical system. The main goal of this research is determination of the relationship between the concentrations of $\mathrm{O}_{3}, \mathrm{OH}$ and $\mathrm{H}_{2} \mathrm{O}$ that would allow us to retrieve vertical distribution of the latter species by vertical distribution of the two first species measured during the CRISTA-MAHRSI campaign. So, the complete MPCS may be reduced substantially for solution of this problem. We are going to consider the most important chemical reactions (see Table 1) only that determine evolution of the constituents of the family of odd oxygen $\mathrm{O}_{\mathrm{x}}\left(\mathrm{O}, \mathrm{O}\left({ }^{1} \mathrm{D}\right)\right.$, and $\left.\mathrm{O}_{3}\right)$ and odd hydrogen $\mathrm{HO}_{\mathrm{x}}\left(\mathrm{H}, \mathrm{OH}\right.$, and $\left.\mathrm{HO}_{2}\right)$ at the heights of $50-90 \mathrm{~km}$ in the time interval $\tau_{0}$ with a duration of approximately one day (daylight hours).

Note, first of all, that the presented list of reactions does not include the reactions that are of minor importance, such as destruction of $\mathrm{O}_{\mathrm{x}}$ constituents due to catalytic cycles of reactions with participation of the families of $\mathrm{ClO}_{\mathrm{x}}$ and $\mathrm{NO}_{\mathrm{x}}$. Brasseur and Solomon (1986) showed that the rate of the destruction, in the first approximation, is proportional to $\mathrm{ClO}_{2}$ and $\mathrm{NO}_{2}$ concentrations, respectively. The concentration of these constituents in the mesosphere during daylight hours is known to decrease dramatically with increasing height, so that already at the height of $50 \mathrm{~km}$ the cumulative sink of $\mathrm{O}_{\mathrm{x}}$ provided by the above mentioned catalytic cycles is approximately 10 times less than the sink of $\mathrm{O}_{\mathrm{x}}$ due to the reactions specified in Table 1 . The reactions with participation of the constituents of the family of even hydrogen $\left(\mathrm{CH}_{4}, \mathrm{H}_{2}, \mathrm{H}_{2} \mathrm{O}_{2}\right)$ were not considered for the same reason. In Sect. 3 of the current work we assess maximum error of retrieval of water vapour concentration as a result of this approximation. Besides, in our earlier work (Kulikov et al., 2006) where we used the COMMA-IAP model (Sonnemann et al., 1998) that includes a complete set of constituents and reactions of the mesospheric photochemical system we also demonstrated that the reactions in Table 1 determine well (to an accuracy not worse than 1-3\%) daytime concentrations of fast constituents of the families of $\mathrm{O}_{\mathrm{x}}$ and $\mathrm{HO}_{\mathrm{x}}$.

Second, the key MPCS parameters governing evolution of the families of odd oxygen and hydrogen are, evidently, the temperature and concentration of air molecules. Third, in spite of the fact that photochemical reactions with participation of $\mathrm{H}_{2} \mathrm{O}$ molecules (see Reactions R7 and R20 in Table 1) are the main source for the family of odd hydrogen, the concentration of this constituent on the considered interval (daytime hours during one day) can be regarded to be 
constant and depending on coordinates only (e.g., Brasseur and Solomon, 1986). The latter circumstance will be used in the method of retrieval of vertical distribution of this important parameter by vertical distribution of $\mathrm{O}, \mathrm{O}\left({ }^{1} \mathrm{D}\right), \mathrm{O}_{3}, \mathrm{H}$, $\mathrm{OH}$, and $\mathrm{HO}_{2}$ that will be described below.

As was stated in Sect. 1, the proposed method is based on the BDM. The zero-dimensional BDM corresponding to the set of reactions listed in Table 1 and describing the daytime evolution of the MPCS with characteristic time scale $\tau_{0}=10^{4}-10^{6} \mathrm{~s}$ at the heights of $75-90 \mathrm{~km}$ was constructed by Feigin et al. (1998). At these heights atomic oxygen concentration has characteristic time of evolution of order $\tau_{0}$, hence, it should be considered to be a slow variable. Below $75 \mathrm{~km}$, the lifetime of $\mathrm{O}$ is markedly shorter, so its concentration at these heights should formally be regarded to be a fast variable. Nevertheless, in the MPCS BDM describing all the mesosphere in a unified manner it is correct to consider O concentration as a slow variable throughout the $50-90 \mathrm{~km}$ range. Concentrations of the remaining constituents $\left(\mathrm{O}\left({ }^{1} \mathrm{D}\right)\right.$, $\mathrm{O}_{3}, \mathrm{H}, \mathrm{OH}$ and $\mathrm{OH}_{2}$ ) are fast variables with lifetimes $<10^{2} \mathrm{~s}$; here $\mathrm{H}, \mathrm{OH}$ and $\mathrm{OH}_{2}$ form a slow family of odd hydrogen $\mathrm{HO}_{\mathrm{x}}$ whose characteristic variation time is of the order of the time of variation of $\mathrm{O}$ concentration at the heights of 75$90 \mathrm{~km}$. Thus, the zero-dimensional MPCS BDM is a system of seven equations, two of which are first-order differential equations with respect to $\mathrm{O}$ and $\mathrm{HO}_{\mathrm{x}}$ concentrations:

$$
\begin{aligned}
& \frac{\mathrm{d}}{\mathrm{dt}}(\mathrm{O})=-\left((\mathrm{R}(1) \cdot \mathrm{M}+\mathrm{R}(4)) \cdot \mathrm{OH}+\mathrm{R}(5) \cdot \mathrm{HO}_{2}\right. \\
& \left.+\mathrm{R}(9) \cdot \mathrm{O}_{2} \cdot \mathrm{M}+\mathrm{R}(10) \cdot \mathrm{O}_{3}+2 \cdot \mathrm{R}(11) \cdot \mathrm{M} \cdot \mathrm{O}\right) \cdot \mathrm{O} \\
& +2 \cdot \mathrm{R}(8) \cdot \mathrm{O}_{2}+\mathrm{R}(16) \cdot \mathrm{O}_{3}
\end{aligned}
$$

$$
\frac{\mathrm{d}}{\mathrm{dt}}\left(\mathrm{HO}_{\mathrm{x}}\right)=-2 \cdot(\mathrm{R}(2)+\mathrm{R}(18)) \cdot \mathrm{H} \cdot \mathrm{HO}_{2}-2 \cdot \mathrm{R}(3) \cdot \mathrm{HO}_{2} \cdot \mathrm{OH}
$$$$
-2 \cdot \mathrm{R}(15) \cdot \mathrm{OH}^{2}-2 \cdot \mathrm{R}(17) \cdot \mathrm{M} \cdot \mathrm{OH} \cdot \mathrm{H}
$$$$
+2 \cdot\left(\mathrm{R}(7)+\mathrm{R}(20) \cdot \mathrm{O}\left({ }^{1} \mathrm{D}\right)\right) \cdot \mathrm{H}_{2} \mathrm{O}
$$

and the remaining equations form a system of algebraic equations that relate values of fast variables to values of slow ("dynamic") variables and to parameters of the BDM:

$$
\begin{aligned}
& \mathrm{H}=\mathrm{HO}_{\mathrm{x}}-\mathrm{OH}-\mathrm{HO}_{2} \\
& \mathrm{HO}_{2}=\frac{\mathrm{R}(6) \cdot \mathrm{O}_{2} \cdot \mathrm{M} \cdot \mathrm{H}+\mathrm{R}(13) \cdot \mathrm{OH} \cdot \mathrm{O}_{3}}{\mathrm{R}(5) \cdot \mathrm{O}+(\mathrm{R}(2)+\mathrm{R}(14)+\mathrm{R}(18)) \cdot \mathrm{H}+\mathrm{R}(3) \cdot \mathrm{OH}} \\
& \mathrm{O}_{3}=\frac{\mathrm{R}(9) \cdot \mathrm{M} \cdot \mathrm{O}_{2} \cdot \mathrm{O}}{\mathrm{R}(10) \cdot \mathrm{O}+\mathrm{R}(12) \cdot \mathrm{H}+\mathrm{R}(13) \cdot \mathrm{OH}+\mathrm{R}(16)} \\
& \mathrm{OH}=\frac{\mathrm{R}(5) \cdot \mathrm{O} \cdot \mathrm{HO}_{2}+\mathrm{R}(12) \cdot \mathrm{H}^{-O_{3}}+2 \cdot \mathrm{R}(14) \cdot \mathrm{H}^{-\mathrm{HO}_{2}}}{\mathrm{R}(4) \cdot \mathrm{O}+\mathrm{R}(13) \cdot \mathrm{O}_{3}+\mathrm{R}(3) \cdot \mathrm{HO}_{2}} \\
& \mathrm{O}\left({ }^{1} \mathrm{D}\right)=\frac{\mathrm{R}(16) \cdot \mathrm{O}_{3}}{\mathrm{R}(19) \cdot \mathrm{M}}
\end{aligned}
$$

In Eqs. (1)-(7), $M$ is air concentration, $R(1)-R(20)$ are the rates of the reactions listed in Table 1; their numerical values used below correspond to the recent Jet Propulsion Laboratory data (Sander et al., 2006).

It is well known that, in the conditions of the real mesosphere, the MGC evolution is strongly affected by transport processes. For evaluation of the influence of different transport mechanisms on MGC evolution with the time scale $\tau_{0}=\left(10^{4}-10^{6}\right) \mathrm{s}$ of interest to us it suffices to compare characteristic time of transport $\tau_{\text {tr }}$ and $\tau_{0}$. Apparently, transport is essential, if $\tau_{\mathrm{tr}} \leq \tau_{0}$. Such a comparison generally demands knowledge of the spatial scale of inhomogeneity of the studied characteristic. For the vertical distributions of MGS concentrations in the mesosphere these scales are $\sim\left(10^{3}-10^{4}\right)$ $\mathrm{m}$ in the vertical direction and $\sim 10^{7} \mathrm{~m}$ in the horizontal direction (see, e.g., Brasseur and Solomon, 1986). Estimates of $\tau_{\text {tr }}$ made for known mechanisms of transport (molecular and eddy diffusion, horizontal and vertical winds, including those caused by different waves) indicate that the influence of transport on the considered MGS evolution is insignificant in the lower mesosphere (heights from 50 to $70-75 \mathrm{~km}$ ), whereas in the upper part of the modeled region (from 70 75 to $90 \mathrm{~km}$ ) vertical eddy diffusion and transport by vertical wind should be taken into account. It is important that, according to the estimates, both these mechanisms are "slow" in the sense pointed out in Sect. 1, i.e., $\tau_{\mathrm{tr}} \approx \tau_{0}$. This means that even these, most essential transport mechanisms do not break "instantaneous equilibrium" of the fast chemical constituents $\mathrm{O}\left({ }^{1} \mathrm{D}\right), \mathrm{O}_{3}, \mathrm{H}, \mathrm{OH}$, and $\mathrm{HO}_{2}$. Their evolution is fully determined by evolution of the "slow" components $\mathrm{O}$ and $\mathrm{HO}_{\mathrm{x}}$ affected by vertical diffusion and wind. In other words, concentrations of the fast components are related to concentrations of the slow components by algebraic Eqs. (3)(7) obtained within the framework of the zero-dimensional BDM throughout the modeled range of heights $(50-90 \mathrm{~km})$. From the said above it follows that the system of BDM MPCS differential equations must contain terms describing transport by eddy diffusion and by vertical wind:

$$
\begin{aligned}
& \frac{\partial}{\partial t} n_{i}=I_{i}-S_{i}+\frac{\partial}{\partial z} D_{z z} \frac{\partial}{\partial z} n_{i}-\frac{\partial}{\partial z}\left(w_{z} \cdot n_{i}\right), \\
& \{n\}_{i=1,2}=\left\{\mathrm{O}, \mathrm{HO}_{\mathrm{x}}\right\}
\end{aligned}
$$

Here, $I_{i}$ and $S_{i}$ are, respectively, photochemical sources and sinks of the concentration $n_{i}$, corresponding to the right-hand sides of Eqs. (1)-(2); $z$ is height, $D_{z z}$ stands for the coefficient of vertical eddy diffusion, and $w_{z}$ is the vertical wind velocity.

In this work we employed, in addition to the MPCS BDM, two more models of mesospheric photochemistry that take into account these types of transport. First, to verify correctness of the algebraic Eqs. (3)-(7) under real conditions we calculated the COMMA-IAP model (Sonnemann et al., 1998). This model describes the range of heights from 30 to $150 \mathrm{~km}$ and contains all reactions that are usually included in a complete MPCS. Besides, within the framework of this model all MPCS components (the fast ones included) were regarded to be dynamic variables and their evolution was 
determined from the corresponding differential equations. We omit description of the testing procedure and only point out that, in the 50-90 km range of heights, the algebraic system of Eqs. (3)-(7) describes correctly (to an accuracy not worse than $1 \%$ at zenith angles of the Sun not more than $70^{0}$ ) the daytime relationship between $\mathrm{O}\left({ }^{1} \mathrm{D}\right), \mathrm{O}_{3}, \mathrm{H}, \mathrm{OH}$, $\mathrm{HO}_{2}, \mathrm{O}$, and $\mathrm{HO}_{\mathrm{x}}$. The algebraic system includes five equations. Note that this amount of a priori relations, with available data about simultaneous values of concentrations of two arbitrary chemical constituents of the MPCS, is quite sufficient for retrieving the values of all the other components of the system and thus for finding values of dynamic variables of the MPCS BDM $\left(\mathrm{O}\right.$ and $\left.\mathrm{HO}_{\mathrm{x}}\right)$ and of nearly all (except terms proportional to $\mathrm{H}_{2} \mathrm{O}$ concentration and those describing transport) terms entering into the right-hand sides of Eqs. (8). This important property of MPCS BDM underlies the proposed method of retrieval of $\mathrm{H}_{2} \mathrm{O}$ concentration that uses data of $\mathrm{O}_{3}$ and $\mathrm{OH}$ measurements and implies the following sequence of operations:

1. Two pairs of vertical distributions of ozone and hydroxyl $\left\{\mathrm{O}_{3}^{\text {in }}(z), \mathrm{OH}^{\text {in }}(z)\right\}$ and $\left\{\mathrm{O}_{3}^{\text {end }}(z), \mathrm{OH}^{\text {end }}(z)\right\}$ concentrations measured during one day (daylight hours) and corresponding to close values of horizontal coordinates (i.e., approximately the same values of longitude and latitude) are selected from available experimental data. The first pair of vertical distributions (morning measurements) $\left\{\mathrm{O}_{3}^{\text {in }}(z), \mathrm{OH}^{\text {in }}(z)\right\}$ must be measured at local time $t_{\text {in }}$ before 10:00 a.m.; the second pair (evening measurements) $\left\{\mathrm{O}_{3}^{\text {end }}(z), \mathrm{OH}^{\text {end }}(z)\right\}$ must be measured at local time $t_{\text {end }}$ after 12 o'clock in the afternoon.

2. The above data are substituted into Eqs. (3)-(7). After that, single-valued solutions of this system relative to unknown variables (concentrations of $\mathrm{O}\left({ }^{1} \mathrm{D}\right), \mathrm{H}, \mathrm{HO}_{2}$, $\mathrm{O}$, and $\mathrm{HO}_{\mathrm{x}}$ ) are found for each specified value of height $z=z_{0}$. As a result we determine two pairs of vertical distributions of dynamic variables of MPCS BDM $\left\{\mathrm{O}^{\text {in }}(z)\right.$, $\left.\mathrm{HO}_{\mathrm{x}}^{\mathrm{in}}(z)\right\}$ and $\left\{\mathrm{O}^{\text {end }}(z), \mathrm{HO}_{\mathrm{x}}^{\text {end }}(z)\right\}$ concentrations corresponding to close values of horizontal coordinates but different instants of local time $t_{\text {in }}$ and $t_{\text {end }}$.

3. The obtained data and Eqs. (8) are used in a special procedure that enables us to retrieve unambiguously vertical distribution of $\mathrm{H}_{2} \mathrm{O}$ concentration. This procedure is detailed in Sect. 3.

To test correctness of the proposed technique we took a one-dimensional (in height) complete MPCS model corresponding to the reactions listed in Table 1. Within the framework of this model, all the components (except for $\mathrm{O}\left({ }^{1} \mathrm{D}\right)$ concentration) were calculated as dynamic variables, with allowance for transport by vertical eddy diffusion and vertical wind. The model "supplied" conjectural data of experiments
$\left(\left\{\mathrm{O}_{3}^{\text {in }}(z), \mathrm{OH}^{\text {in }}(z)\right\}\right.$ and $\left.\left\{\mathrm{O}_{3}^{\text {end }}(z), \mathrm{OH}^{\text {end }}(z)\right\}\right)$ that were calculated for given distributions of water vapor concentrations $\mathrm{H}_{2} \mathrm{O}(z)$ and parameters of vertical transport. Further, we used the algorithm of retrieval of water vapor concentration described above and compared the retrieved and the "true" distribution of $\mathrm{H}_{2} \mathrm{O}(z)$. The numerical scheme for calculation of this model included 200 layers at the heights ranging from 50 to $92 \mathrm{~km}$. Integration was done by Gear's BDF embedded in the Fortran PowerStation with floating time step controlled to a specified relative accuracy of $10^{-4}$. The upper and lower boundary conditions for the concentrations of $\mathrm{O}_{3}, \mathrm{OH}$ and $\mathrm{HO}_{2}$, as well as the lower boundary conditions for the concentrations of $\mathrm{O}$ and $\mathrm{H}$ were chosen to be free: evolution of these variables at the discussed heights was determined by local (photochemical) processes and was calculated by the corresponding zero-dimensional first-order differential equations without allowance for vertical transport processes. Boundary conditions with given flows were taken as the upper boundary for $\mathrm{O}$ and $\mathrm{H}$ concentrations. Vertical wind velocity was taken in the form

$w_{z}=w_{0}+w_{1} \cdot \sin \left(2 \pi t / T_{1}+\varphi_{1}\right)+w_{2} \cdot \sin \left(2 \pi t / T_{2}+\varphi_{2}\right)$,

where $w_{0}$ is mean zonal velocity, $w_{1}, T_{1}, \varphi_{1}, w_{2}, T_{2}, \varphi_{2}$ are the amplitude, period and phase of vertical wind velocity in diurnal and semi-diurnal tides, respectively. Typical summer profiles from the empiric MSIS-E-90 model (Hedin, 1991) were taken as vertical distributions of temperature and air concentration. Besides, the model took into account data on real dependences of photolysis rates of water, ozone and molecular oxygen on height and local zenith angle of the Sun calculated within the framework of the COMMA-IAP model. Values of local zenith angle of the Sun as a function of local time and latitude were calculated in a standard manner.

\section{The procedure of $\mathrm{H}_{2} \mathrm{O}$ retrieval}

Let us first analyze the case of altitudes lower than 70-75 km, where transport processes weakly affect MPCS BDM dynamics, hence, the zero-dimensional BDM of the system of Eqs. (1)-(2) is applicable. $\mathrm{H}_{2} \mathrm{O}$ concentration at a definite height $z=z_{0}$ is determined by the iteration procedure started from an arbitrary initial value of concentration of the given chemical constituent. At each successive iteration step, Eqs. (1)-(2) are calculated within the interval of daylight local time $t \in\left[t_{\text {in }}, t_{\text {end }}\right]$ with a constant value of $\mathrm{H}_{2} \mathrm{O}$ concentration and initial conditions $\left\{\mathrm{O}^{\text {in }}=\mathrm{O}^{\text {in }}\left(z_{0}\right), \mathrm{HO}_{\mathrm{x}}^{\text {in }}=\mathrm{HO}_{\mathrm{x}}^{\text {in }}\left(z_{0}\right)\right\}$, which allows finding values of dynamic variables $\mathrm{O}^{\mathrm{dv}}$ and $\mathrm{HO}_{\mathrm{x}}^{\mathrm{dv}}$ at the time instant $t=t_{\mathrm{end}}$. Further, the value of $\mathrm{H}_{2} \mathrm{O}$ concentration is varied so that the subsequent calculation of the BDM evolution in the considered time interval should ensure a decreased relative difference between $\left\{\mathrm{O}^{\text {end }}=\mathrm{O}^{\text {end }}\left(z_{0}\right)\right.$, $\left.\mathrm{HO}_{\mathrm{x}}^{\text {end }}=\mathrm{HO}_{\mathrm{x}}^{\text {end }}\left(z_{0}\right)\right\}$ and the new values of $\left\{\mathrm{O}^{\mathrm{dv}}, \mathrm{HO}_{\mathrm{x}}^{\mathrm{dv}}\right\}$. The 
final goal of the iteration procedure is finding the value of $\mathrm{H}_{2} \mathrm{O}$ concentration for which the error

$$
S=\left(\mathrm{HO}_{\mathrm{x}}^{\text {end }}-\mathrm{HO}_{\mathrm{x}}^{\mathrm{dv}}\right)^{2} /\left(\mathrm{HO}_{\mathrm{x}}^{\text {end }}\right)^{2}+\left(\mathrm{O}^{\text {end }}-\mathrm{O}^{\mathrm{dv}}\right)^{2} /\left(\mathrm{O}^{\text {end }}\right)^{2}
$$

would be minimal. Our analysis demonstrates that an optimal value of $\mathrm{H}_{2} \mathrm{O}$ concentration can be found using the simplest gradient iteration scheme

$$
\begin{aligned}
& \mathrm{H}_{2} \mathrm{O}^{\text {new }}=\mathrm{H}_{2} \mathrm{O}^{\text {old }}\left(1+\lambda \cdot\left(\mathrm{HO}_{\mathrm{x}}^{\text {end }}-\mathrm{HO}_{\mathrm{x}}^{\mathrm{dv}}\right) / \mathrm{HO}_{\mathrm{x}}^{\text {end }}\right. \\
& \left.+\lambda \cdot\left(\mathrm{O}^{\text {end }}-\mathrm{O}^{\mathrm{dv}}\right) / \mathrm{O}^{\text {end }}\right)
\end{aligned}
$$

Here, $\lambda=$ const $\ll 1 ; \mathrm{H}_{2} \mathrm{O}^{\text {old }}$ and $\mathrm{H}_{2} \mathrm{O}^{\text {new }}$ are, respectively, the current and subsequent values of $\mathrm{H}_{2} \mathrm{O}$ concentration corresponding to one step of the iteration procedure. The process is finished automatically when $S$ amounts to $10^{-8}$. For verification that the found value of $\mathrm{H}_{2} \mathrm{O}$ concentration is unique and corresponds to the global minimum of $S$ the described procedure must be repeated for several, strongly differing initial values of $\mathrm{H}_{2} \mathrm{O}$ concentration. These may be, for instance, values lying in the $0.1 \mathrm{ppmv}$ to $100 \mathrm{ppmv}$ interval that involves the range of possible values of $\mathrm{H}_{2} \mathrm{O}$ concentrations (1-10 ppmv) in the real conditions of the mesosphere.

For retrieving vertical distribution of $\mathrm{H}_{2} \mathrm{O}$ concentration above $\sim 70-75 \mathrm{~km}$ one should take into account transport processes due to vertical eddy diffusion and vertical wind. Therefore, formally one should use at these heights the set of Eqs. (8). Analysis shows that the described above procedure using the zero-dimensional MPCS BDM may be readily generalized for a one-dimensional model, if we have a priori information about vertical distribution of vertical eddy diffusion coefficient $D_{z z}$ and vertical wind velocity $w_{z}$. In the literature, however, values of $D_{z z}$ at a fixed height vary in a broad interval (up to an order of magnitude or more, see, e.g., Hocking, 1992) and are strongly dependent on latitude and season of the year (e.g., Danilov and Kalgin, 1992; Lübken 1993, 1997), whereas characteristics of vertical wind velocity $w_{z}$ in the mesosphere have not been measured at all and numerical models or estimates based on known theoretical relations with measured characteristics of the mesosphere are, actually, the only available source of information about them. Körner and Sonnemann (2001) demonstrated that values of the mean zonal component of vertical wind velocity reach about $1-2 \mathrm{~cm} \mathrm{~s}^{-1}$ at $80-90 \mathrm{~km}$. Characteristic amplitudes of vertical wind velocity variations in diurnal and semidiurnal tides may be found from their relationship with the amplitudes of temperature variations in these atmospheric waves. For example, for the amplitudes of temperature variations in both the tides of about $5 \mathrm{~K}$ typical of the summer upper mesosphere (Singer et al., 2003), the values of $w_{1,2}$ are about $5-10 \mathrm{~cm} \mathrm{~s}^{-1}$.

In addition, allowance for transport in Eqs. (8) demands accurate calculation of the first and second derivatives of dynamic variables along the vertical coordinate, which imposes rather severe requirements on initial data of experiments. In particular, vertical resolution $d z$ of these data must be much less than characteristic scales of variation of MPCS dynamic variables along the vertical coordinate, which may be of order $1 \mathrm{~km}$ or less in the upper mesosphere (e.g., Brasseur and Solomon, 1986). However, $d z$ of almost all satellite campaigns on measuring MGCs of the mesosphere is $2-3 \mathrm{~km}$ and more. For instance, data of CRISTA-MAHRSI that will be considered in Sect. 4 have resolution $d z \sim 2 \mathrm{~km}$. From the said above it follows that it is impossible to use the mathematically correct description of vertical transport (see Eqs. 8) in application to data of measurements because of uncertainty in the choice of $D_{z z}(\mathrm{z})$ and $w_{z}(\mathrm{z})$ as well as because of insufficient altitude resolution of experimental data. Consequently, we first regard vertical transport characteristics to be unknown and infer the corresponding terms in the MPCS BDM equations simultaneously with vertical distribution of $\mathrm{H}_{2} \mathrm{O}$ concentration in the upper mesosphere. Second, we take these terms into account in a simplified form. More specifically, vertical transport is taken into consideration in the equation for $\mathrm{O}$ concentration only, and terms describing transport are represented in the form of an unknown but constant in time (not in altitude!) source (or sink) $I_{\mathrm{O}}$ of $\mathrm{O}$ molecules, whose physical meaning corresponds to the equation

$I_{\mathrm{O}}=<\frac{\partial}{\partial z} D_{z z} \frac{\partial}{\partial z} \mathrm{O}-\frac{\partial}{\partial z}\left(w_{z} \cdot \mathrm{O}\right)>$

Here $\langle\ldots\rangle$ denotes averaging on the time interval $\left[t_{\mathrm{in}}, t_{\mathrm{end}}\right]$. Note that this approach, as before, allows us to use the zerodimensional model but now it is necessary to infer simultaneously two unknown parameters $\left(\mathrm{H}_{2} \mathrm{O}\right.$ and $\left.I_{\mathrm{O}}\right)$. Therefore, the described procedure of retrieving $\mathrm{H}_{2} \mathrm{O}$ concentration is modified. Now, at each iteration, we change not only the value of $\mathrm{H}_{2} \mathrm{O}$ concentration (in accord with Eq. 11) but also the value of $I_{\mathrm{O}}$ whose iterative scheme is written in the form

$I_{\mathrm{O}}^{\text {new }}=I_{\mathrm{O}}^{\mathrm{old}}\left(1+\beta \cdot\left(\mathrm{O}^{\mathrm{end}}-\mathrm{O}^{\mathrm{dv}}\right) / \mathrm{O}^{\text {end }}\right)$,

where $\beta=$ const $\ll 1$. Therefore, for finding $\mathrm{H}_{2} \mathrm{O}$ concentration we have to minimize two errors:

$S_{1}=\left(\mathrm{HO}_{\mathrm{x}}^{\mathrm{end}}-\mathrm{HO}_{\mathrm{x}}^{\mathrm{dv}}\right)^{2} /\left(\mathrm{HO}_{\mathrm{x}}^{\mathrm{end}}\right)^{2}$ and

$S_{2}=\left(\mathrm{O}^{\text {end }}-\mathrm{O}^{\mathrm{dv}}\right)^{2} /\left(\mathrm{O}^{\text {end }}\right)^{2}$

Retrieval of $\mathrm{H}_{2} \mathrm{O}$ concentration ceases automatically as soon as the values of both the quantities $S_{1,2}$ become less than $10^{-8}$.

Note that the proposed procedure neglects the source (or sink)

$I_{\mathrm{HO}_{\mathrm{x}}}=<\frac{\partial}{\partial z} D_{z z} \frac{\partial}{\partial z} \mathrm{HO}_{\mathrm{x}}-\frac{\partial}{\partial z}\left(w_{z} \cdot \mathrm{HO}_{\mathrm{x}}\right)>$

of molecules of the family of odd hydrogen due to vertical transport. This approximation is forced: terms defining $I_{\mathrm{HO}_{\mathrm{x}}}$ enter the right-hand side of the same differential 


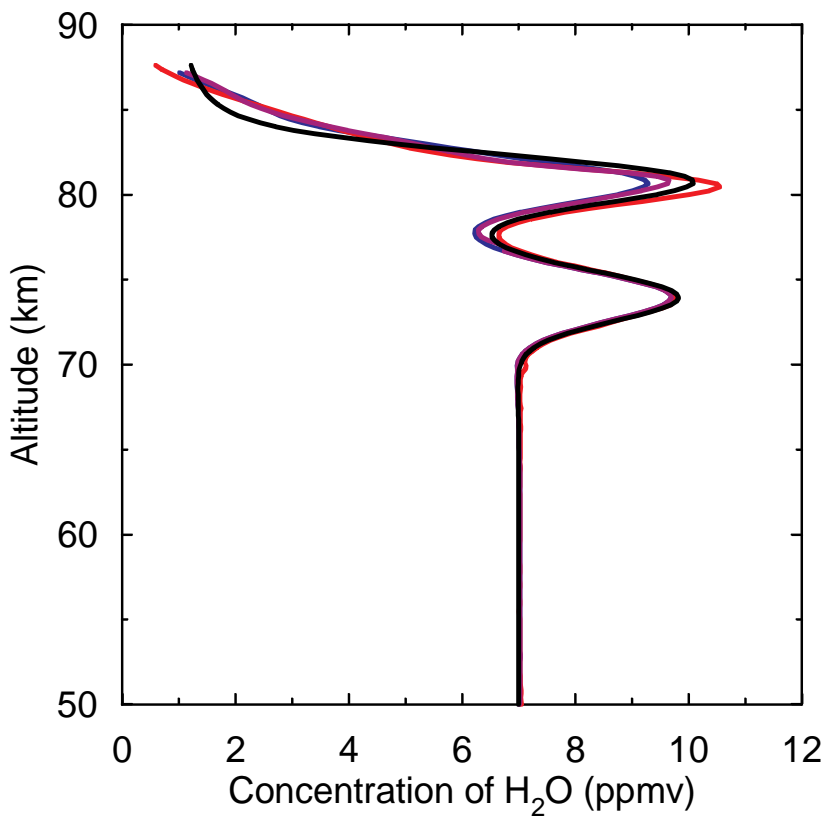

Fig. 1. Model (black curve) and retrieved (red, blue and violet curves) profiles of $\mathrm{H}_{2} \mathrm{O}$ concentration (see the text for details).

Eqs. (8) (for the concentration of $\mathrm{HO}_{\mathrm{x}}$ ) as the source $I_{\mathrm{H}_{2} \mathrm{O}}$ of interest to us. Therefore, in the absence of objective information about distributions of $D_{z z}$ and $w_{z}$ and with insufficient vertical resolution of experimental data we cannot, in principle, retrieve these terms separately. Consequently, following the proposed procedure (for the interval of heights from $70-75 \mathrm{~km}$ to $90 \mathrm{~km}$ ) we find instead of $I_{\mathrm{H}_{2} \mathrm{O}}$ the sum $I_{\mathrm{H}_{2} \mathrm{O}}+I_{\mathrm{HO}_{\mathrm{x}}}$, which leads, generally speaking, to "overestimated" values of retrieved $\mathrm{H}_{2} \mathrm{O}$ concentrations. Error caused by such overestimation is, evidently, determined by vertical distribution of the coefficient of vertical eddy diffusion and characteristic values of vertical velocity. To evaluate possible error, the procedure of retrieval of $\mathrm{H}_{2} \mathrm{O}$ concentration was tested on numerous examples of vertical distributions of $\mathrm{H}_{2} \mathrm{O}$ and $D_{z z}$, both model and typical for the conditions of the summer mesosphere in which the CRISTA-MAHRSI campaign was conducted. Both, $D_{z z}(\mathrm{z})=$ const distributions and the inferred profiles of this parameter borrowed from the works by Danilov and Kalgin (1992), Hocking (1992), Lübken $(1993,1997)$ were used. The testing procedure was described in Sect. 2. Our research revealed that for $D_{z z}(\mathrm{z}) \equiv 0$ and $w_{0,1,2} \equiv 0$ the retrieved profile of $\mathrm{H}_{2} \mathrm{O}$ concentration reproduces almost perfectly (with error less than $1 \%$ ) a "true" profile of $\mathrm{H}_{2} \mathrm{O}$ concentration throughout the modeled range of heights. The least bit pronounced differences appear (first of all at altitudes higher than $80 \mathrm{~km}$ ) at relatively large values of transport parameters: $D_{z z}(\mathrm{z}) \geq 50 \mathrm{~m}^{2} \mathrm{~s}^{-1}$ and $w_{0,1,2} \geq 1 \mathrm{cms}^{-1}$. Essential error $(>50 \%)$ in the retrieved profile of $\mathrm{H}_{2} \mathrm{O}$ concentration (when we can say that the proposed method ceases to work) is observed at $D_{z z}(\mathrm{z}) \geq(4-$
Table 2. Sensitivity (\%) of retrieved values of $\mathrm{H}_{2} \mathrm{O}$ concentration to $1 \%$ uncertainty of initial experimental data.

\begin{tabular}{lllll}
\hline & $\mathrm{O}_{3}^{\text {in }}$ & $\mathrm{OH}^{\text {in }}$ & $\mathrm{O}_{3}^{\text {end }}$ & $\mathrm{OH}^{\text {end }}$ \\
\hline $\mathrm{H}_{2} \mathrm{O}$ & $50-80 \mathrm{~km}: 0-0.1$ & $50-80 \mathrm{~km}: 0-0.05$ & $0-1$ & $1.5-2$ \\
& $80-87 \mathrm{~km}: 0.05-0.3$ & $80-87 \mathrm{~km}: 0.05-0.3$ & & \\
\hline
\end{tabular}

5) $\cdot 10^{2} \mathrm{~m}^{2} \mathrm{~s}^{-1}$ and $w_{0,1,2} \geq(30-50) \mathrm{cm} \mathrm{s}^{-1}$. Note that these values of $D_{z z}$ and $w_{0,1,2}$ are much too high for the summer period. Our analysis demonstrates that the retrieved distributions of $\mathrm{H}_{2} \mathrm{O}$ concentration reproduce well initial model ("true") distributions, both qualitatively and quantitatively up to heights of $85-87 \mathrm{~km}$, if we use the real values of transport parameters. This is illustrated, in particular, in Fig. 1 where we show initial model distribution of $\mathrm{H}_{2} \mathrm{O}(z)$ (black curve) with two pronounced maxima and three profiles of this parameter retrieved by different initial "experimental" data $\left(\left\{\mathrm{O}_{3}^{\text {in }}(z), \mathrm{OH}^{\text {in }}(z)\right\}\right.$ and $\left.\left\{\mathrm{O}_{3}^{\text {end }}(z), \mathrm{OH}^{\text {end }}(z)\right\}\right)$. In all the three considered cases, "experimental" data were calculated from a complete MPCS model with the same preset distribution of $\mathrm{H}_{2} \mathrm{O}(z)$ (black line), but for different distributions of vertical transport parameters and for different instants of local time $t_{\text {in }}$ and $t_{\text {end }}$. The first profile (red curve) was retrieved by data calculated for $D_{z z}(\mathrm{z})=10^{2} \mathrm{~m}^{2} \mathrm{~s}^{-1}, w_{0}=2 \mathrm{~cm} \mathrm{~s}^{-1}$, $w_{1,2}=5 \mathrm{~cm} \mathrm{~s}^{-1}$ and the time instants $t_{\text {in }}=08: 00 \mathrm{a}$ am. and $t_{\text {end }}=02: 00 \mathrm{p} . \mathrm{m}$. The second profile (blue curve) was retrieved by data calculated for $D_{z z}(\mathrm{z})$ Lübken (1993) (the METAL campaign), $w_{0}=2 \mathrm{~cm} \mathrm{~s}^{-1}, w_{1,2}=10 \mathrm{~cm} \mathrm{~s}^{-1}$ and the instants of time $t_{\text {in }}=06: 00 \mathrm{a} . \mathrm{m}$. and $t_{\mathrm{end}}=06: 00 \mathrm{p} . \mathrm{m}$. The third profile (violet curve) was retrieved by data calculated from Lübken (1993) (the NLC 91 campaign), $w_{0}=2 \mathrm{~cm} \mathrm{~s}^{-1}$, $w_{1,2}=10 \mathrm{~cm} \mathrm{~s}^{-1}$ for $t_{\text {in }}=09: 00$ a.m. and $t_{\text {end }}=01: 00$ p.m. One can see that all the three retrieved profiles reproduce satisfactorily model distribution of $\mathrm{H}_{2} \mathrm{O}$ concentration.

We analyzed sensitivity of the retrieved distributions of $\mathrm{H}_{2} \mathrm{O}$ concentration to uncertainty of the values of initial data of experiments (see Table 2) and found that in all the cases $1 \%$ uncertainty of the data leads to moderate fluctuations of $\mathrm{H}_{2} \mathrm{O}$ concentrations that do not exceed 1-2\%. Figure 2 illustrates results of retrieval of $\mathrm{H}_{2} \mathrm{O}$ concentration under the condition that the initial data (both pairs of distributions $\left\{\mathrm{O}_{3}^{\text {in }}(z)\right.$, $\left.\mathrm{OH}^{\text {in }}(z)\right\}$ and $\left.\left\{\mathrm{O}_{3}^{\text {end }}(z), \mathrm{OH}^{\text {end }}(z)\right\}\right)$ "were measured" with the error of 5\%. The uncertainty of retrieved values of $\mathrm{H}_{2} \mathrm{O}$ concentrations as a function of height arising in this case varied within the $\sim(7-12) \%$ range.

It was mentioned in Sect. 2 that all the most essential reactions between $\mathrm{O}, \mathrm{O}\left({ }^{1} \mathrm{D}\right), \mathrm{O}_{3}, \mathrm{H}, \mathrm{OH}$ and $\mathrm{HO}_{2}$ are summarized in Table 1. Some of the reactions that are not included in the table may also affect mesospheric distributions of the above constituents, the most significant of which are reactions with participation of even hydrogen compounds $\mathrm{H}_{2} \mathrm{O}_{2}$, $\mathrm{H}_{2}$ and $\mathrm{CH}_{4}$. We included them in the complete MPCS 
model so as to clarify how these reactions may influence accuracy of retrieval of $\mathrm{H}_{2} \mathrm{O}$ concentration. The mesospheric concentrations of $\mathrm{H}_{2}$ and $\mathrm{CH}_{4}$ change with the characteristic times significantly exceeding one day. Therefore, they were taken into account in the framework of the model as parameters with vertical distributions which are typical for the time and location of the CRISTA-MAHRSI measurements. The characteristic time of variations of the mesospheric $\mathrm{H}_{2} \mathrm{O}_{2}$ concentration is less than one day. Hence, the model included an additional differential equation to calculate evolution of this variable. As in the previous cases, the complete MPCS model complemented in the above way was used to obtain initial "experimental" data $\left(\left\{\mathrm{O}_{3}^{\text {in }}(z), \mathrm{OH}^{\mathrm{in}}(z)\right\}\right.$ and $\left.\left\{\mathrm{O}_{3}^{\text {end }}(z), \mathrm{OH}^{\text {end }}(z)\right\}\right)$ which were used then to retrieve the $\mathrm{H}_{2} \mathrm{O}$ concentration. Our analysis revealed that the neglect of reactions with participation of even hydrogen compounds $\mathrm{H}_{2} \mathrm{O}_{2}, \mathrm{H}_{2}$ and $\mathrm{CH}_{4}$ leads, within the framework of the proposed procedure, to absolute error in retrieved $\mathrm{H}_{2} \mathrm{O}$ concentrations at heights lower than $70 \mathrm{~km}$. Calculations showed that, at $50-70 \mathrm{~km}$, this error does not exceed $\sim 0.2-0.3 \mathrm{ppmv}$, with the average value of error being $\sim 0.1$ ppmv. Bearing in mind that $\mathrm{H}_{2} \mathrm{O}$ concentration in this range of heights is 6-7 ppmv (see e.g., Seele and Hartogh, 1999; Hervig et al., 2003), we are in a position to conclude that the corresponding relative error does not exceed $5 \%$. This result (a secondary role of even hydrogen compounds $\mathrm{H}_{2} \mathrm{O}_{2}, \mathrm{H}_{2}$ and $\mathrm{CH}_{4}$ ) may be elucidated on an example of the reaction $\mathrm{H}_{2}+\mathrm{O}\left({ }^{1} \mathrm{D}\right) \rightarrow \mathrm{H}+\mathrm{OH}$ which is most "influential" among the omitted reactions. At the heights of $50-70 \mathrm{~km}$, the concentration of $\mathrm{H}_{2} \mathrm{O}$ exceeds the $\mathrm{H}_{2}$ concentration by more than 3-4 times (Sonnemann et al., 2005), and the value of the constant of this reaction is less than half of the constant of the reaction $\mathrm{H}_{2} \mathrm{O}+\mathrm{O}\left({ }^{1} \mathrm{D}\right) \rightarrow 2 \mathrm{OH}$. As a result, the contribution of the reaction $\mathrm{H}_{2}+\mathrm{O}\left({ }^{1} \mathrm{D}\right) \rightarrow \mathrm{H}+\mathrm{OH}$ to the common source of odd hydrogen at the heights of $50-70 \mathrm{~km}$ turns out to be considerably smaller than that of the sum of the reactions $\mathrm{H}_{2} \mathrm{O}+\mathrm{O}\left({ }^{1} \mathrm{D}\right) \rightarrow 2 \mathrm{OH}$ and $\mathrm{H}_{2} \mathrm{O}+\mathrm{h} v \rightarrow \mathrm{H}+\mathrm{OH}$. Above $65-70 \mathrm{~km}$, the concentration of $\mathrm{O}\left({ }^{1} \mathrm{D}\right)$ decreases significantly. Hence, at such heights, the reactions employing this component become insignificant compared with the reaction $\mathrm{H}_{2} \mathrm{O}+\mathrm{h} \nu \rightarrow \mathrm{H}+\mathrm{OH}$.

\section{Retrieval of $\mathrm{H}_{2} \mathrm{O}(z)$ from CRISTA-MAHRSI data}

During the second satellite CRISTA-MAHRSI campaign on 8-16 August 1997, vertical distributions of temperature, air concentration and two chemical MPCS constituents $(\mathrm{OH}$ and $\mathrm{O}_{3}$ ) were measured simultaneously (Grossmann et al., 2002; Conway, et al., 2000). Available data on hydroxyl concentration were measured for daytime hours at latitudes and altitudes of $15^{\circ} \mathrm{S}-71^{\circ} \mathrm{N}$ and $40-90 \mathrm{~km}$, respectively, by ozone concentration at $18^{\circ} \mathrm{S}-73^{\circ} \mathrm{N}, 50-94 \mathrm{~km}$, and by air temperature and concentration at $74^{\circ} \mathrm{S}-74^{\circ} \mathrm{N}, 29-91 \mathrm{~km}$. As was noted above, this information is sufficient for inferring, us-

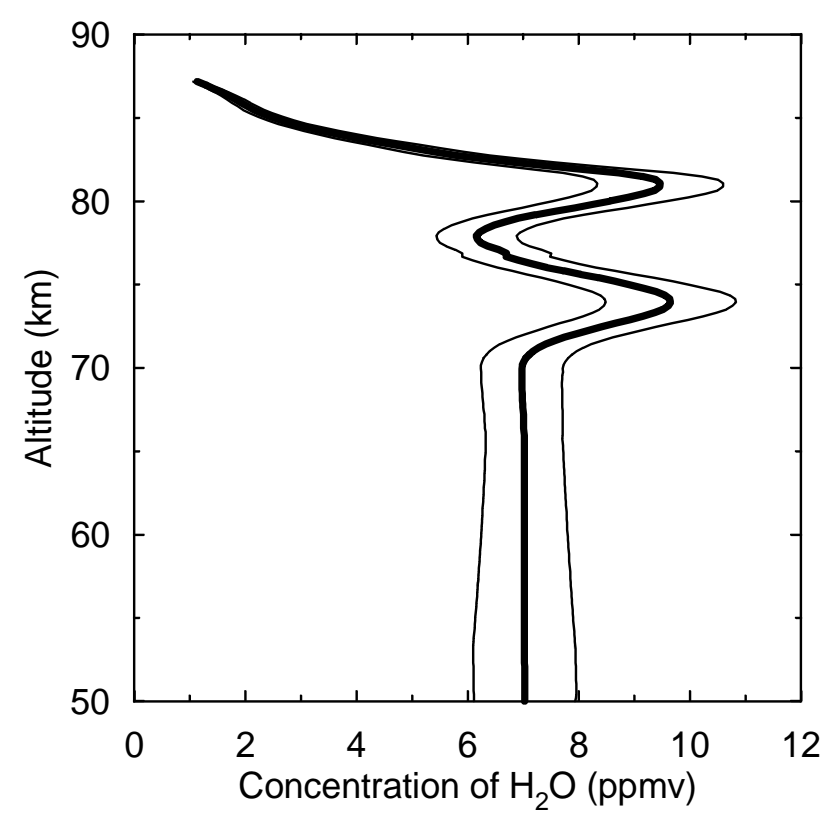

Fig. 2. The same as in Fig. 1 (violet curves), but with allowance for $5 \%$ uncertainty of initial data. The thin lines show uncertainty boundaries of retrieved values of $\mathrm{H}_{2} \mathrm{O}$ concentration.

ing the MPCS BDM algebraic equations, simultaneous vertical distributions of $\mathrm{O}, \mathrm{O}\left({ }^{1} \mathrm{D}\right), \mathrm{H}$, and $\mathrm{HO}_{2}$ concentrations in the mesosphere $(50-87 \mathrm{~km})$ in a wide range of latitudes, longitudes and local times, and for further retrieval of vertical distributions of $\mathrm{H}_{2} \mathrm{O}$. In Fig. 3 we give by way of example vertical distributions of $\mathrm{H}, \mathrm{HO}_{2}, \mathrm{HO}_{\mathrm{x}}$ and $\mathrm{O}$ concentrations obtained from the CRISTA-MAHRSI data measured on 13 August 1997 at $60-63^{\circ} \mathrm{N}, 355-360^{\circ} \mathrm{W}$ at local time instants $t_{\text {in }}=08: 00$ a.m. and $t_{\text {end }}=03: 00$ p.m. Omitting detailed analysis we note that qualitatively the results presented in the figures agree quite well with the available concepts of vertical distribution of these constituents (e.g., Brasseur and Solomon, 1986; Takahashi, et al., 1996; Sandor and Clancy, 1998; Gumbel, et al., 1998). Figure 4 shows vertical distribution of water vapor concentration (heavy solid curve and dark circles) retrieved using the proposed technique and the distribution of dynamic variables of MPCS BDM given in Fig. 3. It is clear from this figure, in particular, that within the considered range of heights $\mathrm{H}_{2} \mathrm{O}(z)$ has two pronounced maxima at $73 \mathrm{~km}$ and $81 \mathrm{~km}$. The second profile of $\mathrm{H}_{2} \mathrm{O}$ depicted in Fig. 4 (heavy dashed curve and open rhombs) was obtained from the CRISTA-MAHRSI data measured on 13 August 1997 at $63-65^{\circ} \mathrm{N}, 225-230^{\circ} \mathrm{W}$ at local time instants $t_{\text {in }}=07: 12 \mathrm{a} . \mathrm{m}$. and $t_{\mathrm{end}}=02: 30 \mathrm{p} . \mathrm{m}$. This profile, like the previous one, has a well pronounced maximum at $73 \mathrm{~km}$. The "upper" maximum is evidently higher than in the first case. We cannot make more definite conclusions as the corresponding CRISTA-MAHRSI data at $\sim 83 \mathrm{~km}$ are "truncated". Note that both the profiles 

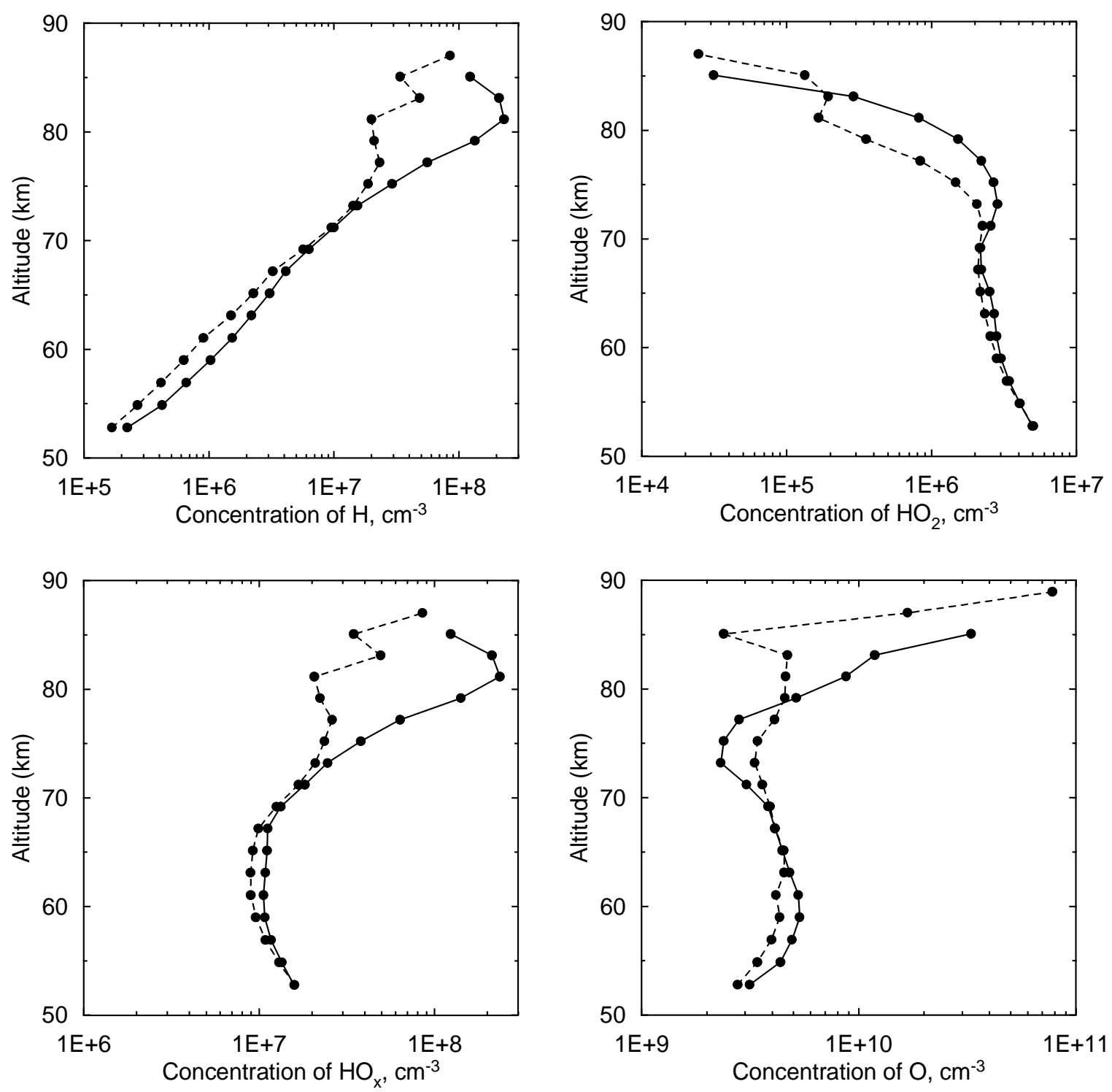

Fig. 3. Vertical distributions of $\mathrm{H}, \mathrm{HO}_{2}, \mathrm{HO}_{\mathrm{x}}$ and $\mathrm{O}$ concentration at the instants of local time about 08:00 a.m. (dashed curve) and 03:00 p.m. (solid curve) retrieved from CRISTA-MAHRSI data measured on 13 August 1997 at $60-63^{\circ} \mathrm{N}, 355-360^{\circ} \mathrm{W}$.

in Fig. 4 correspond to close values of latitude. Nevertheless, they have pronounced qualitative and quantitative differences, evidently because they are strongly spaced apart (by about $4000 \mathrm{~km}$ ) in zonal direction. This conclusion is supported by the results of retrieval of $\mathrm{H}_{2} \mathrm{O}$ concentration presented in Fig. 5 that correspond to the CRISTAMAHRSI data measured on 15 August 1997 at $69-71^{\circ} \mathrm{N}$, $60-65^{\circ} \mathrm{W}$ at $t_{\mathrm{in}}=08: 00$ a.m. and $t_{\mathrm{end}}=00: 18$ p.m. (heavy solid curve and dark circles) and $66-68^{\circ} \mathrm{N}, 141-148^{\circ} \mathrm{W}$ at $t_{\text {in }}=08: 12 \mathrm{a} . \mathrm{m}$. and $t_{\mathrm{end}}=01: 30 \mathrm{p} . \mathrm{m}$. (heavy dashed curve and open rhombs). One can see that in this case two spaced apart profiles agree well up to $73-75 \mathrm{~km}$, but above these heights appreciable quantitative difference (up to $40-50 \%$ ) in the corresponding values of $\mathrm{H}_{2} \mathrm{O}$ concentration is observed.

\section{Discussion}

Note that the presence of two maxima in the distribution of $\mathrm{H}_{2} \mathrm{O}$ concentration at 73 and $81 \mathrm{~km}$ shown by the heavy solid curve and dark circles in Fig. 4 agrees well, both quantitatively and qualitatively, with results of direct measurements. In particular, in Fig. 4 we present for comparison two vertical profiles of water vapour concentration in mesosphere measured by HALOE (v. 19) on 3 and 22 August 1997. Moreover, these maxima are also observed in the HALOE data measured in July-August at $65-70^{\circ} \mathrm{N}$ (McHugh et al., 2003; Hervig et al., 2003) averaged over 10 years. Appearance of the upper maximum may be attributed to redistribution of $\mathrm{H}_{2} \mathrm{O}$ concentration as a result of processes of formation, 


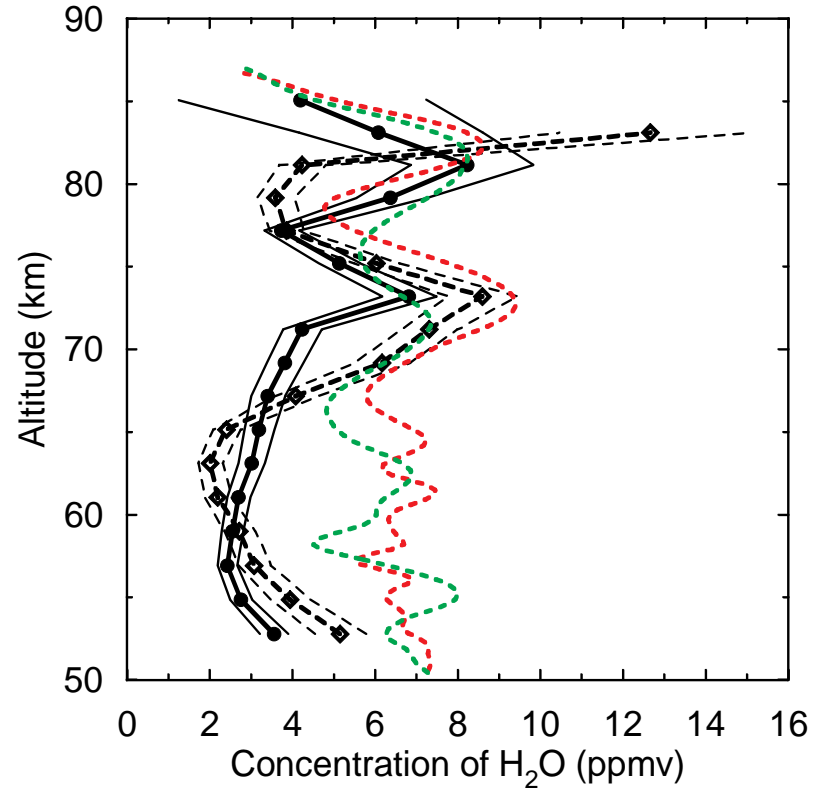

Fig. 4. Profiles of $\mathrm{H}_{2} \mathrm{O}$ concentration retrieved from CRISTAMAHRSI data measured on 13 August 1997 at 60-63 N, 355$360^{\circ} \mathrm{W}$ (heavy solid curve and dark circles) and $63-65^{\circ} \mathrm{N}, 225-$ $230^{\circ} \mathrm{W}$ (heavy dashed curve and open rhombs). The thin curves show retrieval error corresponding to uncertainties of initial experimental data. Profiles of $\mathrm{H}_{2} \mathrm{O}$ concentration measured by HALOE (v.19) on 3 August 1997 at $71.8^{\circ} \mathrm{N}, 160^{\circ} \mathrm{W}$ (dashed red curve) and 22 August 1997 at $70.3^{\circ} \mathrm{N}, 230^{\circ} \mathrm{W}$ (dashed green curve).

sedimentation and evaporation of particles of mesospheric clouds in the summer time at mesopause heights (Summers et al., 2001; Von Zahn and Berger, 2003). A possible cause of the second maximum of $\mathrm{H}_{2} \mathrm{O}$ concentration (at 73-75 km) may be heterogeneous reactions of $\mathrm{H}_{2} \mathrm{O}$ molecule formation on the surface of meteorite dust hypothesized by Summers and Siskind (1999). However, Sonnemann et al. (2005) showed that no heterogeneous reactions are needed to produce the high water vapor peak at $70 \mathrm{~km}$ or higher.

At the same time, below about $65-70 \mathrm{~km}$, our results (see Figs. 4-5) differ appreciably from data of direct measurements. One can see that values of $\mathrm{H}_{2} \mathrm{O}$ concentration retrieved at these heights are about $2-4$ ppmv, whereas according to the HALOE data these values are of order 6-7 ppmv (e.g., Hervig et al., 2003). We believe there are two most probable reasons for this discrepancy:

1. It may be conjectured that real values of constants of photochemical reactions differ strongly from the values recommended by JPL which we use in our research. Summers et al. (2001) showed that $\mathrm{OH}$ concentrations measured within the framework of MAHRSI at 69$71^{\circ} \mathrm{N}$ in the $50-79 \mathrm{~km}$ range of heights proved to be appreciably less (up to 50-60\% less) than those calculated by the photochemical model with allowance for the dis-

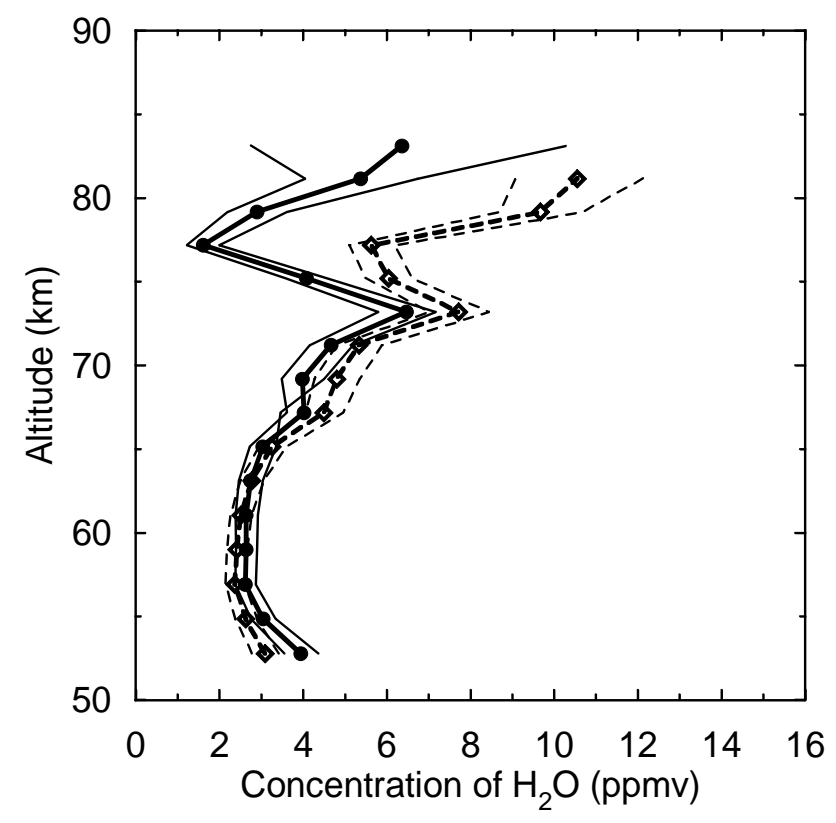

Fig. 5. Profiles of $\mathrm{H}_{2} \mathrm{O}$ concentration retrieved from CRISTAMAHRSI data measured on 15 August 1997 at $69-71^{\circ} \mathrm{N}, 60$ $65^{\circ} \mathrm{W}$ (heavy solid curve and dark circles) and $66-68^{\circ} \mathrm{N}, 141-$ $148^{\circ} \mathrm{W}$ (heavy dashed curve and open rhombs). The thin curves show retrieval error corresponding to uncertainties of initial experimental data.

tribution of $\mathrm{H}_{2} \mathrm{O}$ concentration from HALOE. According to Summers et al. (2001) the cause of this discrepancy is the overestimated (by 50\%) standard JPL value of constant of the reaction $\mathrm{O}+\mathrm{HO}_{2} \rightarrow \mathrm{O}_{2}+\mathrm{OH}$. Figure 6 demonstrates the distribution of $\mathrm{H}_{2} \mathrm{O}$ concentration which we retrieved by the CRISTA-MAHRSI data same as in Fig. 4 (heavy solid curve and dark circles), but for the reaction constant $R(5)=0.5 \cdot R(5)_{\mathrm{JPL}}$. One can see that the change of the value of the reaction constant results in a moderate (by about 2-3 ppmv) increase in the $\mathrm{H}_{2} \mathrm{O}$ concentration at $50-65 \mathrm{~km}$, but is much more pronounced at the heights of the middle mesosphere, resulting, in particular, in a considerable (by about $7 \mathrm{ppmv}$ ) increase in the lower maximum of $\mathrm{H}_{2} \mathrm{O}(z)$. Thus, upon the whole we can state that a change in the constant of the reaction $\mathrm{O}+\mathrm{HO}_{2} \rightarrow \mathrm{O}_{2}+\mathrm{OH}$ does not markedly reduce discrepancy with results of direct measurements of $\mathrm{H}_{2} \mathrm{O}$. Such an analysis was undertaken for other photochemical reactions listed in Table 1, but we failed to find reasonable changes of their constants that would enable us to increase (up to admissible level) characteristic values of $\mathrm{H}_{2} \mathrm{O}$ concentration below $65-70 \mathrm{~km}$ without substantial growth of concentration of this constituent above these heights. 


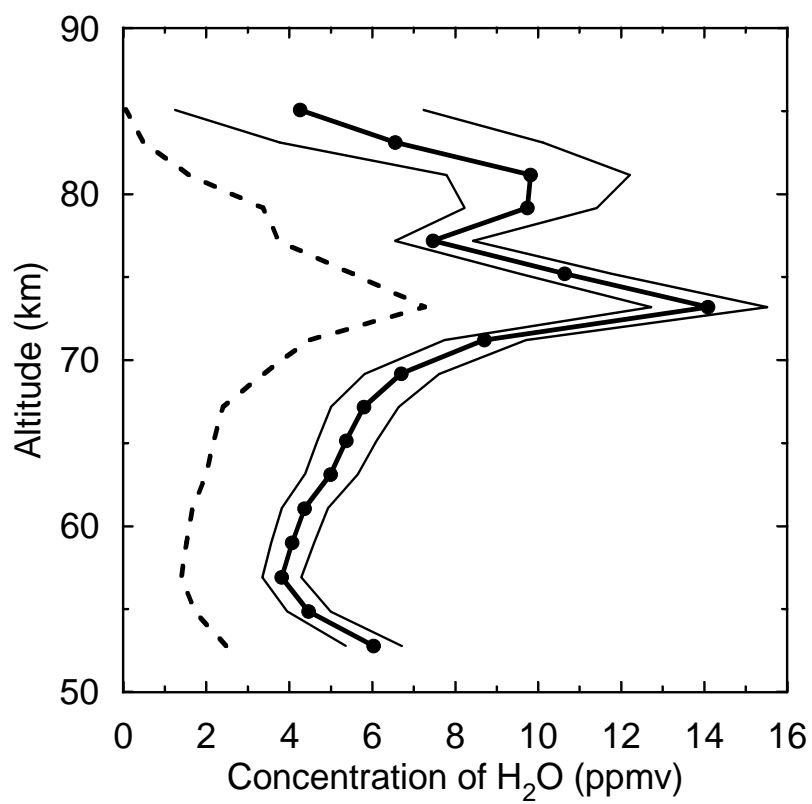

Fig. 6. The solid curves show vertical distribution of $\mathrm{H}_{2} \mathrm{O}$ concentration retrieved from the same CRISTA-MAHRSI data as in Fig. 4 (heavy solid curve and dark circles), but for $\mathrm{O}+\mathrm{HO}_{2} \rightarrow \mathrm{O}_{2}+\mathrm{OH}$ $\mathrm{R}(5)=0.5 \cdot \mathrm{R}(5)_{\mathrm{JPL}}$. The dashed curve shows an increase in $\mathrm{H}_{2} \mathrm{O}$ concentration as a function of height as a result of decreasing reaction constant.

2. The used data of $\mathrm{OH}$ concentration measurements at the heights of $50-70 \mathrm{~km}$ may be underestimated. In other words, the discrepancy noted by Summers et al. (2001) between the model and measured concentrations of $\mathrm{OH}$ may be due to unrecorded error of MAHRSI measurements. This possibility is pointed to indirectly by data of simultaneous balloon-borne measurements of vertical distributions of $\mathrm{OH}, \mathrm{HO}_{2}, \mathrm{O}_{3}$ and $\mathrm{H}_{2} \mathrm{O}$ at $69^{\circ} \mathrm{N}$ made by means of FIRS-2 at the heights of 30-50 km (Jucks et al., 1998) the same year as the MAHRSI campaign. Jucks et al. (1998) showed that the OH concentrations measured by FIRS-2 agree well with model calculations with reaction constants complying with the JPL recommendations. Besides, direct comparison of data at $44-50 \mathrm{~km}$ given by Jucks et al. (1998) with results of MAHRSI measurements demonstrates that "satellite" concentrations of $\mathrm{OH}$ prove to be less than data of more accurate balloon-borne measurements (please see Fig. 7). Relative value of this difference $\left(\mathrm{OH}_{\mathrm{FIRS}}{ }^{-}\right.$ $\mathrm{OH}_{\text {MAHRSI }} / \mathrm{OH}_{\text {MAHRSI }}$ ) grows with increasing height and amounts to about $33 \%$ already at $50 \mathrm{~km}$. Note also that the value of $\mathrm{OH}_{\mathrm{FIRS}} \approx 1.76 \cdot 10^{7} \mathrm{~cm}^{-3}$ at $50 \mathrm{~km}$ corresponds almost exactly to the model value of the $\mathrm{OH}$ concentration at the same height, which was calculated by Summers et al. (2001) using the photochemical model with account for the distribution of $\mathrm{H}_{2} \mathrm{O}$ concentration from HALOE and, as opined by Sum-

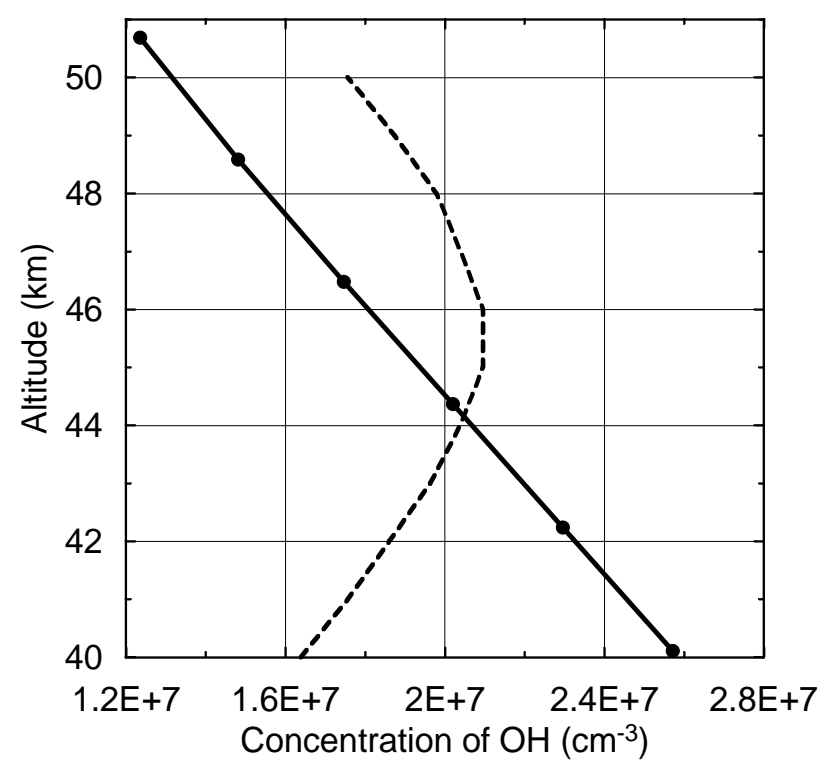

Fig. 7. The solid curve shows vertical distribution of $\mathrm{OH}$ concentration at 40-50 km averaged over eight profiles of $\mathrm{OH}$ concentration obtained in MAHRSI campaign, which were used to retrieve vertical distribution of $\mathrm{H}_{2} \mathrm{O}$ concentration in Figs. 4 and 5. The dashed curve shows vertical distribution of $\mathrm{OH}$ concentration from Jucks et al. (1998) measured by FIRS-2 on 30 April 1997 at $69^{\circ} \mathrm{N}$ (see explanations in the text).

mers et al. (2001), is overestimated. Thus, given underestimated MAHRSI data, one can hypothesize that measurement error of $\mathrm{OH}$ concentration above $50 \mathrm{~km}$ reaches even higher values, which, in the final analysis, explains low values of $\mathrm{H}_{2} \mathrm{O}$ concentration at $50-70 \mathrm{~km}$ shown in Figs. 4-5.

To conclude, we note that the proposed method of water vapour retrieval in mesosphere implies that the magnitude of this parameter at specific altitude weakly changes within several hours (4-7 h). This supposition may be violated in some cases, for example, near the boundary of a polar vortex where water vapour concentration has an appreciable meridional gradient and gravity waves impact the boundary (Lossow et al., 2009). In such nontrivial situations experimental data with high temporal resolution are required for retrieving water vapour concentration using the basic dynamic model of mesospheric photochemical system.

\section{Conclusions}

We propose an indirect method for retrieval of a number of significant minor gas constituents of the atmosphere. The technique is based on the use of models of atmospheric photochemical systems simplified in a special manner. It is applied to results of simultaneous satellite CRISTA-MAHRSI 
measurements of $\mathrm{O}_{3}$ and $\mathrm{OH}$ concentrations aimed at retrieving vertical distributions of $\mathrm{H}_{2} \mathrm{O}$ concentrations in the mesosphere. It should be noted that the method may be applied to other atmospheric photochemical systems in troposphere and stratosphere.

Acknowledgements. The authors thank D. Offermann, M. Kaufmann, O. Gusev, and M. H. Stevens for the CRISTA-MAHRSI data they made available to us. The work was done under support of the RFBR (projects 06-02-16568 and 09-05-01041) and of the Program of Fundamental Research of the RAS Department of Physical Sciences "Physics of the Atmosphere: Electric Processes, Radiophysical Methods of Researches" (project 2.1).

Edited by: F.-J. Lübken

\section{References}

Brasseur, G. and Solomon, S.: Aeronomy of the Middle Atmosphere, 452 pp., D. Reidel, Norwell, Mass., 1986.

Conway, R. R., Summers, M. E., Stevens, M. H., Cardon, J. G., Preusse, P., and Offermann, D.: Satellite observations of upper stratospheric and mesospheric $\mathrm{OH}$ : The $\mathrm{HO}_{\mathrm{x}}$ dilemma, Geophys. Res. Lett., 27, 2613-2616, 2000.

Danilov, A. D. and Kalgin, U. A.: Seasonal and latitudinal variations of eddy diffusion-coefficient in the mesosphere and lower thermosphere, J. Atmos. Terr. Phys., 54, 1481-1489, 1992.

Feigin, A. M. and Konovalov, I. B.: On the possibility of complicated dynamic behaviour of atmospheric photochemical systems: Instability of the Antarctic photochemistry during the ozone hole formation, J. Geophys. Res., 101(D), 26023-26038, 1996.

Feigin, A. M., Konovalov, I. B., and Molkov, Y. I.: Towards understanding nonlinear nature of atmospheric photochemistry: Essential dynamic model of the mesospheric photochemical system, J. Geophys. Res., 103, 25447-25460, 1998.

Fichtelmann, B. and Sonnemann, G.: On the variation of ozone in the upper mesosphere and lower thermosphere: a comparison between theory and observation, J. Meteorol., 39, 297-308, 1989.

Grossmann, K. U., Offermann, D., Gusev, O., Oberheide, J., Riese, M., and Spang, R.: The CRISTA-2 mission, J. Geophys. Res., 107(D23), 8173, doi:10.1029/2001JD000667, 2002.

Gumbel, J., Murtagh, D. P., Espy, P. J., Witt, G., and Schmidlin, F. J.: Odd oxygen measurements during the Noctilucent Cloud 93 rocket campaign, J. Geophys. Res., 103, 23399-23414, 1998.

Hedin, A. E.: Extension of the MSIS thermospheric model into the middle and lower atmosphere, J. Geophys. Res., 96, 1159-1172, 1991.

Hervig, M., McHugh, M., and Summers, M. E.: Water vapor enhancement in the polar summer mesosphere and its relationship to polar mesospheric clouds, Geophys. Res. Lett., 30(20), 2041, doi:10.1029/2003GL018089, 2003.

Hocking, W. K.: Turbulence in the region $80-120$ km, Adv. Space Res., 50, 153-161, 1990.

Jucks, K. W., Johnson, D. G., Chance, K. V., Traub, W. A., Margitan, J. J., Osterman, G. B., Salawitch, R. J., and Sasano, Y.: Observations of $\mathrm{OH}, \mathrm{HO}_{2}, \mathrm{H}_{2} \mathrm{O}$, and $\mathrm{O}_{3}$ in the upper stratosphere: implications for $\mathrm{HO}_{\mathrm{x}}$ photochemistry, Geophys. Res. Lett., 25, 3935-3938, 1998.
Körner, U. and Sonnemann, G. R.: Global three-dimensional modeling of the water vapor concentration of the mesospheremesopause region and implications with respect to the noctilucent cloud region, J. Geophys. Res., 106, 9639-9651, 2001.

Kulikov, M. Y., Feigin, A. M., and Sonnemann, G. R.: Retrieval of the vertical distribution of chemical components in the mesosphere from simultaneous measurements of ozone and hydroxyl distributions, Radiophysics and Quantum Electronics, 49, 683691, 2006.

Lossow, S., Khaplanov, M., Gumbel, J., Stegman, J., Witt, G., Dalin, P., Kirkwood, S., Schmidlin, F. J., Fricke, K. H., and Blum, U.: Middle atmospheric water vapour and dynamics in the vicinity of the polar vortex during the Hygrosonde-2 campaign, Atmos. Chem. Phys., 9, 4407-4417, 2009, http://www.atmos-chem-phys.net/9/4407/2009/.

Lübken, F. J.: Experimental results on the role of turbulence for the heat budget of the upper atmosphere, Habilitation Thesis, 160 pp., Bonn University, 1993.

Lübken, F. J.: Seasonal variation of turbulent energy dissipation rates at high latitudes as determined by in situ measurements of neutral density fluctuations, J. Geophys. Res., 102, 1344113456, 1997.

McHugh, M., Hervig, M., Magill, B., Thompson, R. E., Remsberg, E., Wrotny, J., and Russell III, J.: Improved mesospheric temperature, water vapor and polar mesospheric cloud extinctions from HALOE, Geophys. Res. Lett., 30(8), 1440, doi:10.1029/2002GL016859, 2003.

Sander, S. P., Finlayson-Pitts, B. J., Friedl, R. R., Golden, D. M., Huie, R. E., Keller-Rudek, H., Kolb, C. E., Kurylo, M. J., Molina, M. J., Moortgat, G. K., Orkin, V. L., Ravishankara, A. R., and Wine, P. W.: Chemical Kinetics and Photochemical Data for Use in Atmospheric Studies, Evaluation Number 15, JPL Publication 06-2, Jet Propulsion Laboratory, Pasadena, p. 523, 2006.

Sandor, B. J. and Clancy, R. T.: Mesospheric $\mathrm{HO}_{\mathrm{x}}$ chemistry from diurnal microwave observations of $\mathrm{HO}_{2}, \mathrm{O}_{3}$, and $\mathrm{H}_{2} \mathrm{O}$, J. Geophys. Res., 103, 13337-13351, 1998.

Seele, C. and Hartogh, P.: Water vapor of the polar middle atmosphere: Annual variation and summer mesosphere conditions as observed by ground-based microwave spectroscopy, Geophys. Res. Lett., 26, 1517-1520, 1999.

Singer, W., Bremer, J., Hocking, W. K., Weiss, J., Latteck, R., and Zecha, M.: Temperature and wind tides around the summer mesopause at middle and Arctic latitudes, Adv. Space Res., 31(9), 2055-2060, 2003.

Sonnemann, G., Kremp, C., Ebel, A., and Berger, U.: A threedimensional dynamic model of the minor constituents of the mesosphere, Atmos. Environ., 32, 3157-3172, 1998.

Sonnemann, G. R., Grygalashvyly, M., and Berger, U.: Autocatalytic water vapor production as a source of large mixing ratios within the middle to upper mesosphere, J. Geophys. Res., 110, D15303, doi:10.1029/2004JD005593, 2005.

Summers, M. E. and Siskind, D. E.: Surface recombination of O and $\mathrm{H}_{2}$ on meteoric dust as a source of mesospheric water vapor, Geophys. Res. Lett., 26, 1837-1840, 1999.

Summers, M. E., Conway, R. R., Englert, C. R., Siskind, D. E., Stevens, M. H., Russell, J. M., Gordley, L. L., and McHugh, M. J.: Discovery of a water vapor layer in the Arctic summer mesosphere: Implications for polar mesospheric clouds, Geophys. Res. Lett., 28, 3601-3604, 2001. 
Takahashi, H., Melo, S. M. L., Clemesha, B. R., Simonich, D. M., Stegman, J., and Witt, G.: Atomic hydrogen and ozone concentrations derived from simultaneous lidar and rocket airglow measurements in the equatorial region, J. Geophys. Res., 101, 40334040, 1996. von Zahn, U. and Berger, U.: Persistent ice cloud in the midsummer upper mesosphere at high latitudes: Three-dimensional modeling and cloud interactions with ambient water vapor, J. Geophys. Res., 108(D8), 8451, doi:10.1029/2002JD002409, 2003. 